\title{
Expression of Tubulin Beta II in Neural Stem/Progenitor Cells and Radial Fibers During Human Fetal Brain Development
}

\author{
Yasuhiro Nakamura, Munehiko Yamamoto, Eriko Oda, Atsuyo Yamamoto, \\ Yonehiro Kanemura, Masayuki Hara, Akira Suzuki, Mami Yamasaki, and \\ Hideyuki Okano
}

Department of Pathology (YN), St. Mary's Hospital, and Department of Chemistry (MY, EO), Kurume University School of Medicine, Kurume, and Tissue Engineering Research Center (YN, MY, EO, AY, YK, MH, MY, HO), National Institute of Advanced Industrial Science and Technology, Amagasak, Department of Neuroanatomy (AS, HO), Osaka University Graduate School of Medicine, Suita, and Institute for Clinical Research (YK, MY) and Department of Neurosurgery (MY), Osaka National Hospital, Chuo-ku, Osaka, and Core Research for Evolutional Science and Technology (AS, HO), Japan Science and Technology Corporation (JST), Saitama, and Department of Physiology (HO), Keio University School of Medicine, Tokyo, Japan

\begin{abstract}
SUMMARY: Recent studies revealed that the "radial glia" in fetal rodent brains are dividing neuronal precursor cells. However, in fetal primate brains, this issue remains unclear, with previous reports indicating that radial glia are a specialized form of astroglia. To investigate the relationship between radial fibers (RFs) and neural stem/progenitor cells in the fetal human brain, we generated polyclonal antibodies to human nestin protein and developed a new mAb, KNY-379, by screening for antibodies that immunostained RFs on paraffin-embedded human fetal brain specimens (12 gestational weeks). The immunostaining for KNY-379 antigen and nestin was seen over the RFs in brains at 8 gestational weeks. Furthermore, KNY-379 antigen and nestin were also detected in human neural stem/progenitor cells in neurosphere cultures. At 12 to 15 gestational weeks, the KNY-379 immunostaining of RFs remained in the periventricular zone and the deep part of the intermediate zone, but it also appeared in outgrowing axons in the cortical plate, in the superficial portion of the intermediate zone, and in apical dendrites in the molecular layer. In the later stages of fetal development (18-40 gestational weeks), this antigen remained in the outgrowing axons and dendrites, but was no longer associated with RFs. Expression cloning and immunoblot analysis demonstrated the antigen to be tubulin beta II, which would thus be a good marker for studying RFs and neural stem/progenitor cells in the early developing human brain. (Lab Invest 2003, 83:479-489).
\end{abstract}

\begin{abstract}
$\mathrm{n}$ the developing mammalian brain, young postmi1 totic neurons leave the periventricular zone (PV) and migrate to the cortical plate (CP) along radial fibers (RFs) that extend from the cells of the periventricular neuroepithelium and terminate in branches at the pial surface of the cortex (reviewed in Bentivoglio and Mazzarello, 1999; Rakic, 1972; Walsh and Cepko, 1992). RFs are the processes of cells known as "radial cells," which have been termed differently by various researchers (His, 1889; Fujita, 1963; Noctor et al, 2001; Rakic, 1972; Ramon and Cajal, 1911). Radial
\end{abstract}

\section{DOI: 10.1097/01.LAB.0000063930.75913.B3}

Received January 22, 2003.

This study was supported by Health Sciences Research Grants for Specific Diseases "Intractable Hydrocephalus" (1999-SD-17) from the Ministry of Health and Welfare, Japan.

Address reprint requests to: Dr. Yasubiro Nakamura, Department of Pathology, St. Mary's Hospital, 422, Tsubukuhon-machi, Kurume-shi, Japan 830-8543. E-mail:naka@st-mary-med.or.jp cells located in the PV of the fetal monkey have been thought to be a specialized cell type belonging to the astroglial lineage, based on their expression of glial fibrillary acidic protein (GFAP) (Levitt et al, 1981) and thus have been termed "radial glia" (Bentivoglio and Mazzarello, 1999). Accordingly, RFs have been called "radial glial fibers" (Rakic, 1995).

Recent progress in neurobiology has led to a new understanding of the development and cell lineages of mammalian brain cells, specifically that neurons and glial cells derive from common progenitor cells, ie, neural stem cells (McKay, 1997). Neural stem/progenitor cells have been found in the PV in both fetal and adult human brains (Buc-Caron, 1995; Keyoung et al, 2001; Kukekov et al, 1999; Pincus et al, 1997; Roy et al, 2000). Furthermore, many lines of recent evidence suggest that some radial cells may generate neurons and that RFs are the cell processes of neural stem/ progenitor cells, at least in fetal mouse brains (Hartfuss et al, 2001; Malatesta et al, 2000; Miyata et al, 2001; Noctor et al, 2001; Parnavelas and Nadarajah, 2001). 
Several immunohistochemical markers for RFs, including intermediate filaments, such as nestin (Hockfield and McKay, 1985; Lendahl et al, 1990) and vimentin (Kamei et al, 1998; Sarnet, 1998; Yachnis et al, 1993), have been reported. Other markers associated with RFs include antigens for the RC1 and RC2 antibodies (Edwards et al, 1990; Misson et al, 1988), brain lipid-binding protein (Feng and Heintz, 1995), bone morphogenetic protein-6 (Schluesenser and Meyermann, 1994), receptor-type protein tyrosine phosphatase-beta (Canoll et al, 1993), glutamine synthetase (Akimoto et al, 1993), and 3CB2 antigen (Prada et al, 1995). However, few studies have recently been attempted to characterize the RFs in developing human fetal brain, especially their relationship to the neural stem/progenitor cells.

To address this issue, in the present study we generated polyclonal antibodies to human nestin protein and developed a new mAb, KNY-379, which recognized RFs in situ within developing human fetal brains as well as neural progenitor cells, including neural stem cells, in human neurospheres that are enriched in these cells. Thus, at least some populations of human fetal RF are likely to be neural stem/ progenitor cells. We also demonstrated by expression cloning that the antigen of KNY-379 is tubulin beta II. Thus, this study provides new tools with which to study the stem cell biology and developmental biology of the human brain.

\section{Results}

\section{mAb KNY-379 and Polyclonal Antibody to Nestin}

The antibody KNY-379 was found to belong to the IgG1, $\kappa$ subclass of immunoglobulins. Both KNY-379 and polyclonal antibody to nestin reacted with paraffin-embedded human and rat tissues and with fresh-frozen sections.

\section{Light Microscopic Immunohistochemistry}

mAb KNY-379 and antibodies against vimentin (pretreated by microwaving), nestin (pretreated by incubation in a hot water bath), GFAP (pretreated by microwaving), and tubulin beta III were immunoreactive on both paraffin-embedded and fresh-frozen sections. The mAb KNY-379 demonstrated strong immunoreactivity in paraffin sections, with a longer postmortem interval equal to 12 hours (longest postmortem interval in our study).

In the cerebrum at 8 gestational weeks (GW), the distribution of the immunopositive staining with KNY379 was similar to that seen with the antibodies to vimentin (Fig. 1, A and B) and to nestin (Fig. 1, D and $\mathrm{E}$ ) in the PV and intermediate zone (IZ), suggesting the presence of the KNY-379 antigen along the RFs in PV and IZ. This colocalization was confirmed by double immunostaining with KNY-379 and anti-vimentin or anti-nestin antibodies (Fig. 1, C and F). Staining for tubulin beta III was negative in the PV and along the RF. The immunoreactivities with GFAP and neurofilament protein (NF) were completely negative at $8 \mathrm{GW}$.
In the cerebrum at 10 to $15 \mathrm{GW}$, positive immunostaining with KNY-379 occurred in a fibrous pattern in the PV and CP. In the IZ, the pattern of positive staining was fibrous and reticular in the deep zone of the IZ and horizontal in the superficial IZ (Fig. 2A). The pattern of immunoreactivity with anti-vimentin was similar to that of KNY-379 in the PV, but it was different in the IZ. The immunoreactivity with antivimentin became weak in the superficial $I Z$ and $C P$ (Fig. 2B). The immunoreactivity with anti-nestin was similar to that of anti-vimentin except for positive staining in the molecular layer (ML) (Fig. 2C). Tubulin beta III immunoreactivity was negative in the PV but positive in the $\mathrm{IZ}$ and $\mathrm{CP}$. The immunoreactivities with GFAP and NF were negative between 10 and 15 weeks.

In the cerebrum at 18 to $40 \mathrm{GW}$, positive fibrous immunoreactivity with KNY-379 was confined to the CP (Fig. 3A). In the IZ, diffuse positive immunoreactivity was seen that diminished gradually. Immunoreactivity, which was probably a result of the invading ends of dendrites and axons, was strong in the $\mathrm{ML}$ over the cerebral convexities but somewhat weak in the sulcal depths. The positive immunoreactivity with antivimentin remained along the RFs as a bead-like pattern in the fading PV and in the deep zone of the IZ; but immunoreactivity was negative in the superficial $I Z$, $\mathrm{CP}$, and $\mathrm{ML}$ (Fig. 3B). Nestin-positive staining was seen in the RFs of the deep IZ up to $18 \mathrm{GW}$; thereafter, the RFs were negative for nestin. The RFs were also positive with GFAP antiserum. A small number of the vimentin-positive glial progenitor cells/glioblasts were immunopositive for KNY-379. Mature astrocytes showed positive immunostaining with antibodies to vimentin and GFAP but were negative with KNY-379 and nestin on serial sections. Galactocerebrosidepositive oligodendrocytes were also negative with KNY-379 and nestin on serial sections (data not shown).

Postnatally, the positive staining with KNY-379 had weakened in all layers except for the ML (not shown). The vimentin/GFAP-positive RFs disappeared after 6 months of age (not shown). The immunoreactivity with KNY-379 emerged again in some apical dendrites and/or axons of cortical neurons after 1 year of age (Fig. 4A) and in some axons in the white matter. These dendrites and axons were also positively stained with the antibody to tubulin beta III and NF (Fig. 4B). The distribution of immunoreactivity to the different antibodies is summarized in the Table.

In the cerebellum, the ML was immunopositive with KNY-379 throughout the fetal period and some apical dendrites and/or axons in the ML, the granular layer, and the white matter became positive with KNY-379 postnatally. In the brain stem and spinal cord, nerve tracts were positive for KNY-379. Positive immunoreactivity in the brain stem was present throughout the fetal, postnatal, adolescent, and adult periods. Cilia of the ependymal cells lining the ventricular system were also strongly positive with KNY-379. No positive immunoreactivity was found when the primary antibod- 

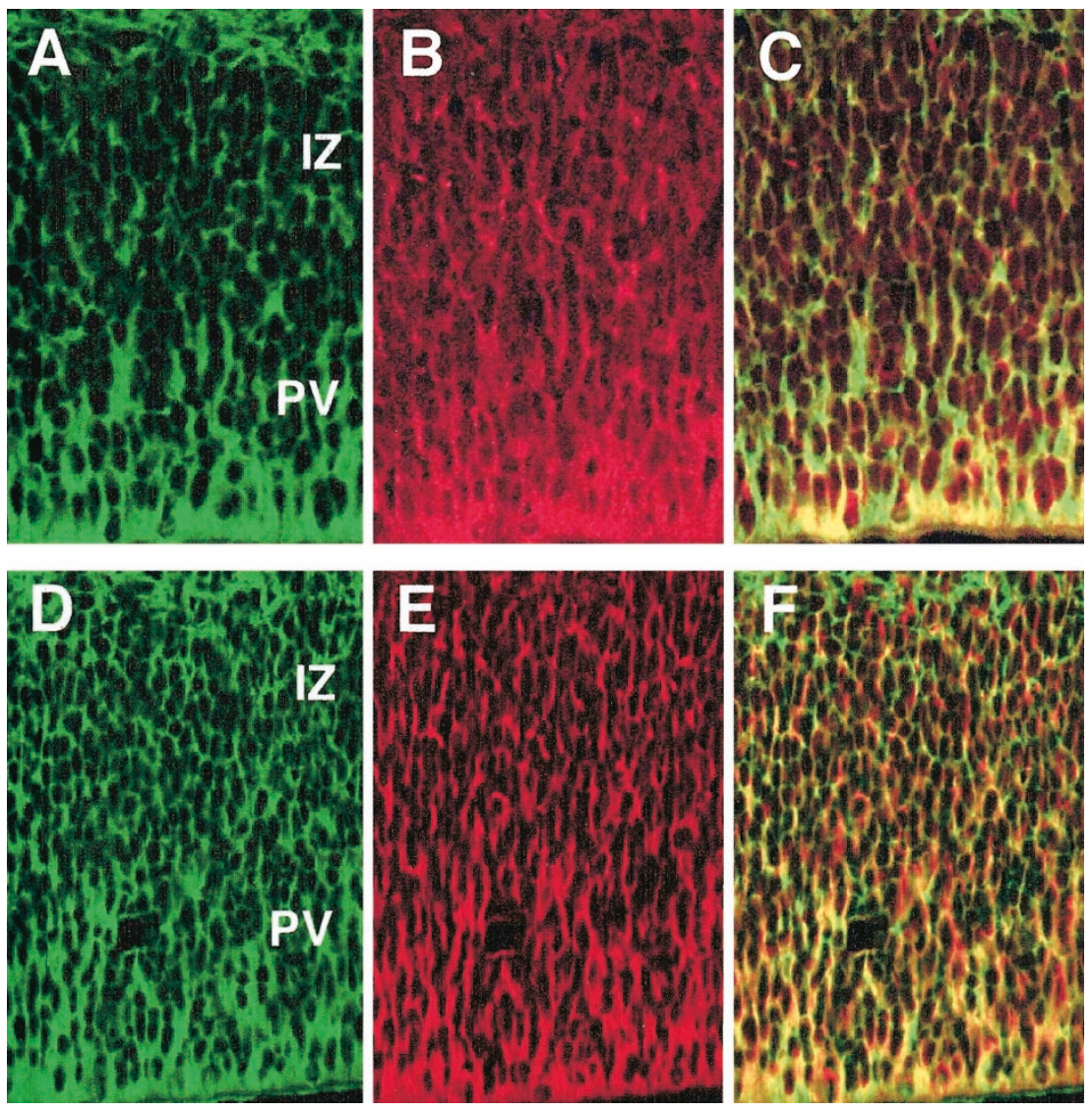

Figure 1.

Immunohistochemical distribution of tubulin beta II, vimentin, and nestin in the cerebrum at 8 gestational weeks (GW). A, Positive immunoreactivity with tubulin beta II (green) was found in the periventricular zone (PV) and intermediate zone (IZ) as a fibrous pattern. B, Positive staining with vimentin (red) was similar to that of tubulin beta II. C, Double immunostaining with tubulin beta II and vimentin suggests that both proteins were associated with radial fibers (RFs). D, Immunohistochemical distribution of tubulin beta II (green). E, Immunohistochemical distribution of nestin (red). F, Double immunostaining with tubulin beta II and nestin suggests that both proteins were associated with RFs (without counterstaining, $\times 100$ ).

ies were omitted or primary antibodies preadsorbed with excess homogenate or normal sera were used.

\section{Expressional Cloning}

Three positive plaques were obtained by expression cloning, using a cDNA library from fetal brains and KNY-379, and 600 to 700 bp of each entrapped cDNA was sequenced. We searched for the CDNA sequence using the BLASTN 2.0.11 program, and a homology search was also made. All three cDNAs were identified (99-100\%) as tubulin beta II. Thus, antibody KNY-379 recognizes tubulin beta II.

\section{Immunoprecipitation and Immunoblotting}

Standard Western blot showed double bands with a major band at $53 \mathrm{kDa}$ and a minor band at $29 \mathrm{kDa}$ in all samples (21, 27, 31, and $40 \mathrm{GW}$ and adult brain). KNY-379 detected a single band at $53 \mathrm{kDa}$ in immunoprecipitates in all samples (Fig. 5). The single band at $53 \mathrm{kDa}$ precipitated with KNY-379 should thus correspond to tubulin beta II as reported previously (Moody et al, 1996). The bands found in standard Western blot and a single band in immunoprecipitates did not react with anti-vimentin or anti-nestin antibod- ies (not shown), indicating that this anti-tubulin beta II antibody did not cross-react with vimentin or nestin. A minor band at $29 \mathrm{kDa}$ found in standard Western blot could be the cross-reactivity with a related protein of tubulin beta II.

\section{Immunocytochemical Study on Human Cultured Neural Cells}

The majority of cells within neurospheres stained positively with KNY-379 (tubulin beta II) as well as Musashi1 and nestin antibodies (Fig. 6). After differentiation was induced, the distribution of the immunoreactive tubulin beta II was similar to that of PSANCAM, indicating that it was expressed in the neural differentiated lineage (Fig. 7). A small number of tubulin beta II-positive cells also appeared to be positively immunoreactive with GFAP (Fig. 7).

\section{Discussion}

Tubulin is a major component protein of microtubules and exists as a heterodimer of two subunits designated alpha and beta. In vertebrates, the alpha and beta tubulins are encoded by small multigene families (Cleveland et al, 1980). In mammals, there are multiple 


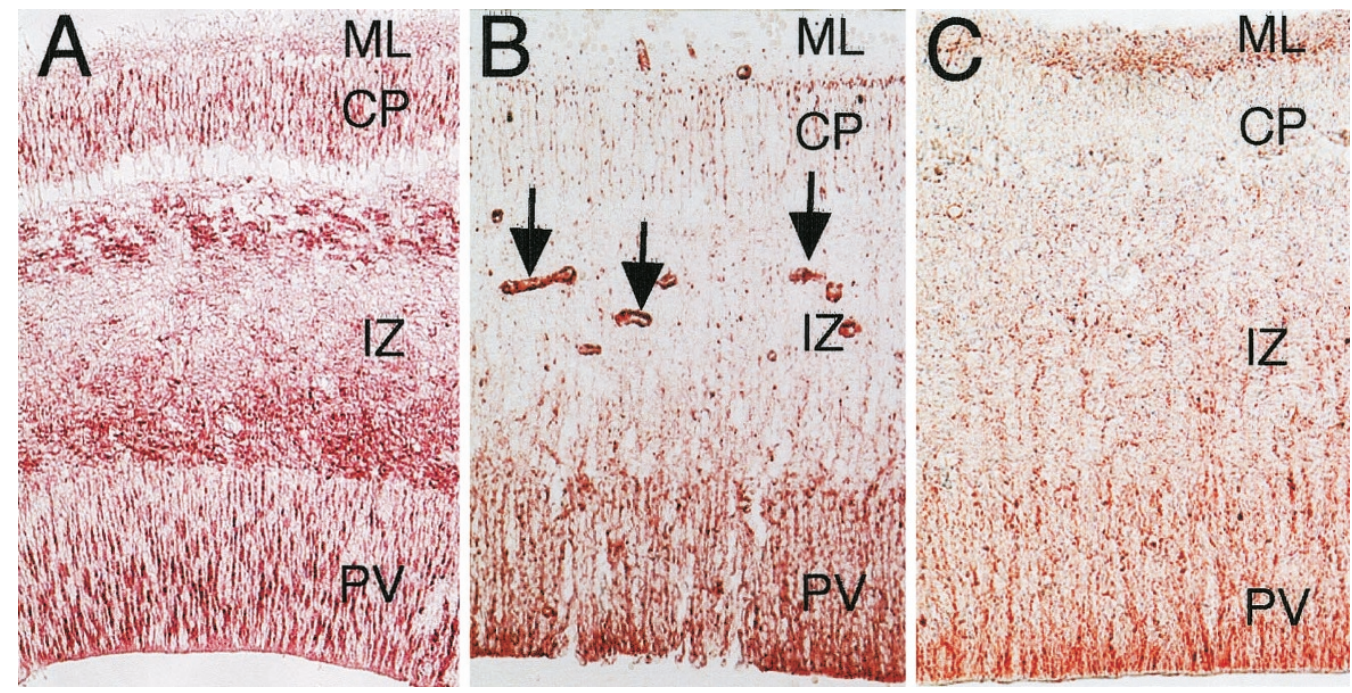

Figure 2.

Immunohistochemical distribution of tubulin beta II, vimentin, and nestin in the cerebrum at $12 \mathrm{GW}$. A, Positive immunoreactivity with tubulin beta II was fibrillary in the PV and cortical plate (CP), fibrillary/reticular in the deep zone of the IZ, and horizontal in the superficial IZ. B, Positive immunostaining for vimentin was fibrillary, but weak in the superficial IZ and CP. Arrows show the positive immunoreactivity in vascular walls. C, The immunoreactivity to nestin was similar to that of vimentin except for positive staining in the molecular layer $(\mathrm{ML})$ (without counterstaining, $\times 25$ ).
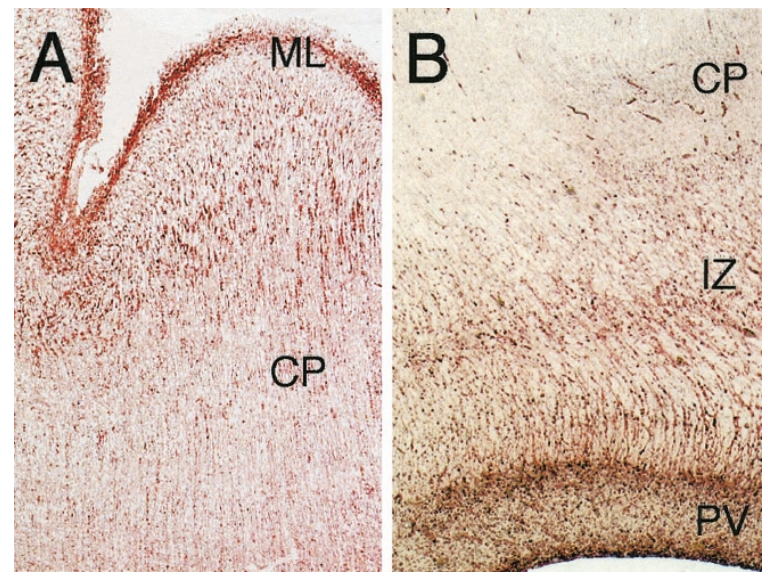

\section{Figure 3.}

Immunohistochemical distribution of tubulin beta II and vimentin in the cerebrum at $25 \mathrm{GW}$. A, positive fibrillary immunoreactivities to tubulin beta II remained only in the $\mathrm{CP}$. $\mathrm{B}$, Positive immunoreactivity with vimentin was found along the RF in the PV and the deep zone of the IZ but not in the superficial $\mathrm{IZ}$ and $\mathrm{CP}$ (without counterstaining: $\mathrm{A}, \times 25 ; \mathrm{B}, \times 12$ ).

isotypes of alpha and beta tubulin encoded by six $\alpha$-tubulin and seven $\beta$-tubulin genes (Cleveland, 1987). Among the seven $\beta$-tubulins, tubulin beta I is expressed constitutively in many tissues. Beta II is the major form of tubulin beta found in neurons and is also present in many other tissues. Beta III is neuron specific, beta IVa is expressed in the nervous system and other tissues, beta IVb is expressed mainly in the testis, beta $V$ is expressed in many tissues except for neurons, and beta VI is specific for hematopoietic tissues (Sullivan, 1988). The different $\beta$-tubulin types are highly homologous throughout most of their sequences. A major variable region exists at the carboxyl terminus (Sullivan, 1988).

The mAb KNY-379, raised against the brains of 14-day-old rat embryos, which correspond to human

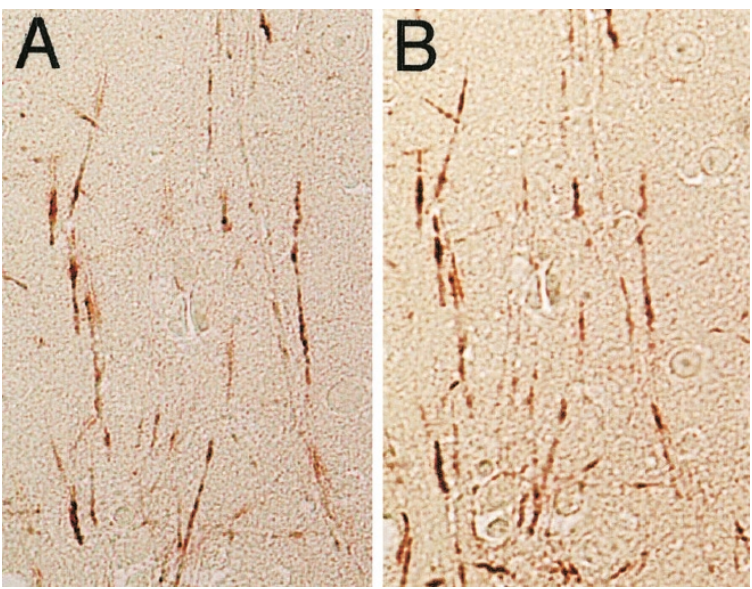

\section{Figure 4.}

Immunohistochemical distribution of tubulin beta II and neurofilament protein (NF) in the serial sections of cerebral cortex at 10 years of age. The positive immunoreactivity of tubulin beta II is seen in some apical dendrites and axons. $\mathrm{B}$, Positive reactivity of NF follows the same pattern (without counterstaining, $\times 100)$.

fetuses of 12 to $16 \mathrm{GW}$, recognizes tubulin beta II in human and rat tissues. Purified bovine brain tubulin contains tubulin beta that is comprised of $3 \%$ type I, $58 \%$ type II, 25\% type III, and 13\% type IV (Banerjee et al, 1988). Thus, tubulin beta II is the major form of tubulin beta in bovine brain, although it is not specific for the nervous system and is also expressed in lung, chick embryo fibroblasts, and Schwann cells (Lewis et al, 1985; Lopata and Cleveland, 1987; Robertson et al, 1992). Tubulin beta III, which is specific for neurons, has been studied extensively. The initial expression of tubulin beta III begins during or immediately after the completion of mitosis in neuroblasts (Lee et al, 1990). However, in frog embryos, tubulin beta II is the neuron-specific form and is expressed in embryonic 
Table 1. Immunohistochemical Distribution of Studied Antigens

\begin{tabular}{|c|c|c|c|c|c|c|}
\hline & Nes & Vim & Tub II & GFAP & Tub III & NF \\
\hline \multicolumn{7}{|l|}{$8 \mathrm{GW}$} \\
\hline Neural stem/progenitor cell & + & + & + & - & - & - \\
\hline Radial fiber & + & + & + & - & - & - \\
\hline \multicolumn{7}{|l|}{10 to $15 \mathrm{GW}$} \\
\hline Neural stem/progenitor cell & + & + & + & - & - & - \\
\hline Radial fiber & + & + & + & - & - & - \\
\hline Migrating neuroblast & - & - & - & - & - & - \\
\hline Neuronal cells in CP & - & - & + & - & + & - \\
\hline \multicolumn{7}{|l|}{18 to $40 \mathrm{GW}$} \\
\hline Radial fiber & $+1-$ & + & - & + & - & - \\
\hline Glial progenitor cells & - & + & $+1-$ & + & - & - \\
\hline Astrocyte & - & + & - & + & - & - \\
\hline Oligodendrocyte & - & - & - & - & - & - \\
\hline Neuronal cell & - & - & + & - & + & + \\
\hline \multicolumn{7}{|l|}{ Adult brain } \\
\hline Astrocyte & - & $+1-$ & - & + & - & - \\
\hline Oligodendrocyte & - & - & - & - & - & - \\
\hline Neuronal cell & - & - & + & - & + & + \\
\hline
\end{tabular}

GW, gestational weeks; Nes, nestin; Vim, vimentin; GFAP, glial fibrillary acidic protein; Tub II, tubulin beta II; Tub III, tubulin beta III; NF, neurofilament protein; $\mathrm{CP}$, cortical plate.

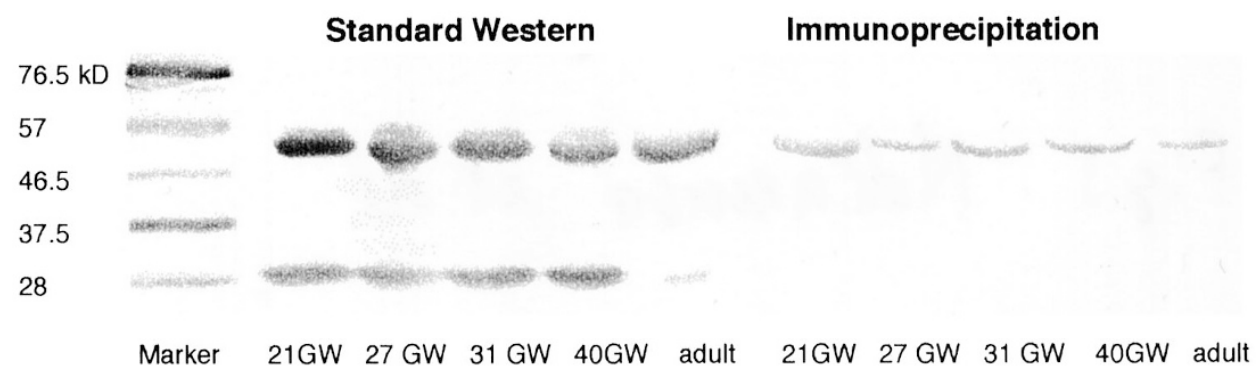

Figure 5 .

Western blotting analysis of tubulin beta II expression in developing brains at 21, 27, 31, and 40 GW and in adult brain. Standard Western blot with KNY-379 showed double bands with a major band at approximately $53 \mathrm{kDa}$ and a minor band at approximately $29 \mathrm{kDa}$ in all brain samples. Immunoprecipitates obtained with KNY-379 showed a single band at approximately $53 \mathrm{kDa}$ in all samples.

neurons but not in radial glia (Moody et al, 1996). In animal brains, tubulin beta II (Hoffman and Cleveland, 1988; Jiang and Oblinger, 1992; Paden et al, 1995) is induced significantly during development and axonal regeneration and is distributed mainly in neuronal components, but its expression in developing human brains has been little studied.

The present study clearly demonstrated that tubulin beta II, as well as vimentin and nestin, the markers for RFs, are expressed over the RFs in the human cerebrum at $8 \mathrm{GW}$. At 10 to $15 \mathrm{GW}$, the presence of tubulin beta II in the PV and the deep zone of the IZ remained the same as at 8 weeks, but the superficial zone of the $\mathrm{IZ}$ and CP showed a more complex pattern of positive staining, possibly reflecting tubulin beta II in outgrowing axons in addition to RFs. In the CP, although weak positive staining was seen for vimentin and nestin, staining for tubulin beta II was strongly positive as a fibrillary pattern. It was recently reported that the cortical RFs could generate neurogenesis based on a study in Pax 6 mutant mice (Heins et al, 2002). The positive signal for tubulin beta II could be attributed to dendrites and to outgrowing axons in the CP and IZ or to changes in the antigenicities of RFs themselves. The findings that the immunoreactive GFAP and NF were completely negative in developing brains during 8-15 weeks gestation may suggest that RFs and outgrowing axons are in the progenitor state without markers for mature glial and neuronal differentiation. After $18 \mathrm{GW}$, the positive fibrillary immunoreactivity of tubulin beta II remained only in the CP and had faded in the IZ. It is reported that RFs themselves remain in these structures even in the postnatal period (Yachnis et al, 1993). This study showed that vimentin and GFAP are present in RFs after $18 \mathrm{GW}$ and up to 6 months after birth. RFs in this stage could be called radial glial fibers because of differentiation into glia expressing GFAP. Although vimentin was seen in astrocytes and glial progenitor cells/glioblasts, tubulin beta II was only found in some glial progenitor cells/ glioblasts and not at all in mature astrocytes.

It is not clear why the positive reactivity of tubulin beta II was reduced in the cerebrum postnatally, but it may be important for the development and mainte- 

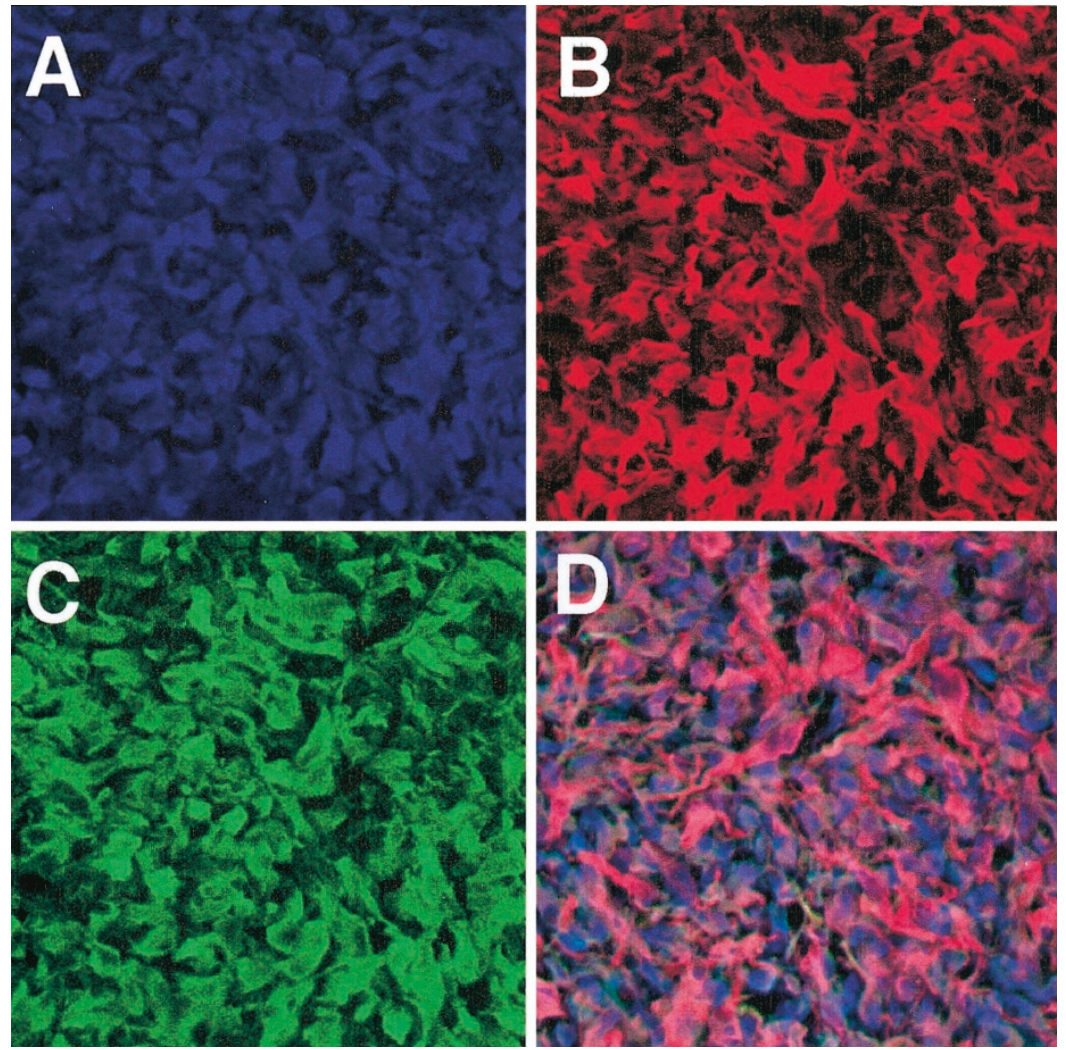

Figure 6.

Immunocytochemical distribution of Musashi1 (A, blue), nestin (B, red), and tubulin beta II ( , green) in human neurosphere cells. All three proteins were expressed in undifferentiated human neurosphere cells. D, Triple-colored immunofluorescence staining revealed the three antigens were distributed similarly in human neurosphere cells $(\times 800)$.

nance of progenitor-state RFs, outgrowing axons, and dendrites in the developing brain. After cells differentiate into glia and neurons, tubulin beta II may no longer be expressed. Strong positive staining for tubulin beta II in the ML of the cerebrum and cerebellum and differences in the staining intensity in cerebral sulci suggest the important and unique roles of the $\mathrm{ML}$ in the developing brain. One microtubule-associated protein (MAP), MAP 5, is expressed strongly in the cerebral and cerebellar ML (Ohyu et al, 1997). MAP 2 and a phosphorylated MAP $1 \mathrm{~B}$ are found in the developing brain and considered important for axonal outgrowth and maintenance (Honig et al, 1996; Nothias et al, 1996).

In this study, we confirmed that tubulin beta II is expressed in Musashi1 and nestin double-positive cells within neurospheres. Previously, the expression of Musashi1 and nestin was carefully studied by the infection of adenoviruses bearing the gene for green fluorescence protein in neural stem/progenitor cells, and the results showed that cells that bore both proteins were able to self renew and cogenerated neurons and glia (Keyoung et al, 2001). Neural stem cells can be selectively expanded in a serum-free defined medium containing epidermal growth factor and/or fibroblast growth factor 2, in which they give rise to a floating cell mass called a "neurosphere" (Reynolds et al, 1992; Svendsen et al, 2001). Cells within neurospheres derived from human fetal brain, which include a population with self-renewing ability and multipotency, are mostly immunopositive against anti-nestin and anti-Musashi1 antibodies. Moreover, we also observed that tubulin beta II was expressed in neuronal progenitor cells and developing neurons that express PSA-NCAM (Seki and Arai, 1993). These findings indicate that tubulin beta II is expressed in human neural stem/progenitor cells and/or neuronal lineage cells, consistent with the results from our immunohistochemical analysis.

On the other hand, in developing human brain tissue in situ after $18 \mathrm{GW}$ and in differentiation-induced neuronal cells in vitro, some cells were immunopositive for both GFAP and tubulin beta II. These findings suggest that tubulin beta II is transiently expressed in glial progenitor cells (glioblasts).

The results of the present study indicate that tubulin beta II may function as a temporary constituent of progenitor-stage RFs that guide neuroblast migration and that it may be important for axonal and dendrite outgrowth thereafter, with other associated proteins such as MAP 1B and 2. We conclude that tubulin beta II is a useful marker for RFs and as such should reveal valuable information for understanding human brain development. However, the function of the tubulin beta II in neural stem/progenitor cells or RFs remains to be elucidated. Future studies using targeted disruption of the mouse tubulin beta II gene should unequivocally reveal the in vivo function of this gene product. 

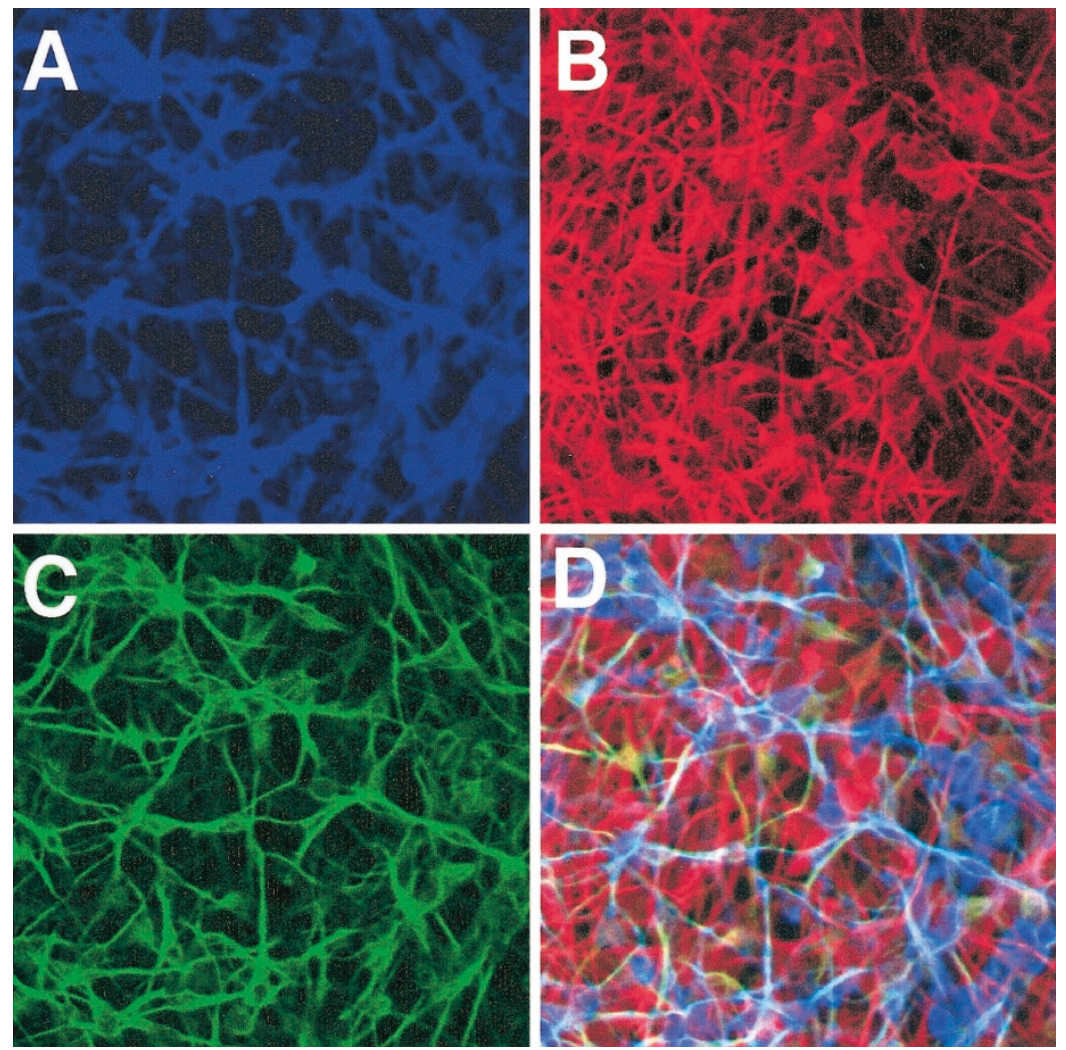

Figure 7.

Immunocytochemical distribution of PSA-NCAM (A, blue), glial fibrillary acidic protein (GFAP) (B, red), and tubulin beta II (C, green) in differentiated neural stem cells The distribution of immunoreactivity against PSA-NCAM and tubulin beta II was quite similar. D, Triple-colored immunofluorescence staining confirmed a similar distribution of PSA-NCAM and tubulin beta II on differentiated cells, indicating neuronal differentiation. Some similarity to the distribution of GFAP was also found, suggesting that tubulin beta II might be expressed in the progenitor stage (or glioblast) of glial differentiation $(\times 800)$.

\section{Materials and Methods}

\section{Human Brain Samples}

Human brain samples for immunohistochemical study were obtained from abortions and at autopsy from 32 cases ranging from $8 \mathrm{GW}$ to 82 years $(2$ at $8 \mathrm{GW}, 1$ at $10 \mathrm{GW}, 1$ at $11 \mathrm{GW}, 2$ at $12 \mathrm{GW}, 1$ at $13 \mathrm{GW}, 1$ at 14 GW, 1 at $15 \mathrm{GW}, 6$ at $18-30 \mathrm{GW}, 5$ at $30-40 \mathrm{GW}, 2$ at 7-28 days after birth, 2 at 3 or 6 months of age, 2 at 1 year, 1 at 5 years, 1 at 10 years, and 4 at 30-82 years). All fetus samples before $20 \mathrm{GW}$ were from spontaneous or electively performed abortions and were fixed in formalin. Other samples were obtained at autopsy. All cases had no abnormalities in the central nervous system. For immunohistochemistry, buffered formalinfixed and paraffin-embedded sections were also prepared from the brains. Some samples obtained at autopsy were placed in liquid nitrogen for immunoprecipitation and Western blot preparations.

For cell culture preparations, forebrain tissue from human fetuses at 7 to $10 \mathrm{GW}$ were obtained from routine legal terminations performed at the Osaka National Hospital with the approval of the ethical committee of the hospital.

Approval to use human fetal neural tissues was obtained from the ethical committees of each institution. Tissue procurement was in accordance with the Declaration of Helsinki (1964) and in agreement with the ethical guidelines of the European Network for Transplantation (NECTA) and the Japan Society of Obstetrics and Gynecology.

\section{mAbs}

For the preparation of monoclonal antibodies, homogenates were obtained from the brains of 14-day embryonal rat fetuses. Monoclonal antibodies were produced by the fusion of FO1 mouse myeloma cells with inguinal lymph node B lymphocytes from female BALB/c mice immunized with three subcutaneous injections of $200 \mathrm{mg}$ of homogenate each, with the Ribi adjuvant system (Funakoshi, Tokyo) (Orlik and Altaner, 1988). Approximately $10^{8}$ lymphocytes were obtained from the inguinal lymph nodes of 8 to 10 mice by rubbing the tissue between two frosted glass slides. The obtained lymphocytes were fused with 2 to $4 \times 10^{7} \mathrm{FO}-1$ cells by adding $50 \%$ polyethylene glycol (Sigma-Aldrich Japan, Tokyo, Japan). HAT (SigmaAldrich) medium selection was performed in $5 \times$ 96-well plates with feeder cells (mice thymocytes) and growth factors (Bryclone, Dainippon-pharm, Osaka, Japan). Hybridoma culture supernatants from 480 wells were screened by incubating them with paraffinembedded sections of developing human brain (12 GW). Approximately one fifth of supernatants were immunoreactive on the paraffin-embedded sections. 
Only one clone produced antibody that reacted with RFs. It was named KNY-379 after the well number. The hybridoma cells were subcloned three times by limiting dilution and injected into the peritoneal cavity of pristane-pretreated mice. The ascites fluid was obtained approximately 1 week later. The Ig subclass was determined using a kit (Amersham Pharmacia Biotech, Sweden) according to the instructions of the manufacturer. The IgG fractions were purified on a protein G-Sepharose column. For the procedures using animals, we followed the Guide for the Care and Use of Laboratory Animals (1985).

\section{Creation of Antibodies Against Human Nestin Protein}

Antibodies against human Nestin protein were prepared as described previously (Nakanishi et al, 2001). Briefly, rabbits were immunized with a synthetic polypeptide corresponding to the C-terminal portion (1596-1610 amino acids) of the human Nestin protein (Dahlstrand et al, 1992) (GenBank accession no. X65964). To enhance its antigenicity, the peptide was covalently attached to activated keyhole limpet hemocyanin (Pierce Chemical, Rockford, Illinois) before immunization. The same Nestin peptide was immobilized on CNBr-activated Sepharose 4B (Amersham Pharmacia Biotech, Buckinghamshire, United Kingdom) for affinity purification of the peptide-specific antibodies. Immunoglobulins adsorbed to the peptide resin were eluted with $0.2 \mathrm{M}$ glycine- $\mathrm{HCl}$ buffer $(\mathrm{pH} 2.7)$ and then neutralized by adding $2 \mathrm{M}$ Tris- $\mathrm{HCl}$ buffer $(\mathrm{pH}$ 8.0). The specificity of the antibody was confirmed by ELISA with the peptide used for the immunization and by immunohistochemical reaction to fetal human brains (based on the characteristic staining of the RFs (Fig. 2C) and human neurosphere cells (Fig. 6B).

\section{Light Microscopic Immunohistochemical Study}

Paraffin-embedded specimens were used for immunohistochemistry according to previously reported methods (Nakamura et al, 1998) with 3-amino-9ethylcarbazole as the chromophore. For immunohistochemical double staining, the methods are described under "Immunocytochemical Analysis" using mouse mAb KNY-379 and goat polyclonal vimentin antibody or rabbit polyclonal nestin antibody and confocal microscopy. Serial sections were used for the study of colocalization of tubulin beta II and NF or tubulin beta III or galactocerebroside. In this study, the antibody KNY-379 and antibodies against vimentin (mouse monoclonal [DAKO, Carpinteria, California] and goat polyclonal [Chemicon, Temecula, California]), nestin, GFAP (DAKO), tubulin beta III (mouse monoclonal [BABCO, Richmond, California]), NF (70 and $200 \mathrm{kDa}$; mouse monoclonal [DAKO]), and galactocerebroside (mouse monoclonal [Chemicon]) were used. In some cases, the slides were pretreated (antigen rescue) by microwaving them for 15 minutes in $10 \mathrm{~mm}$ citrate buffer at $\mathrm{pH} 6.0$ or incubating them in a hot water bath $\left(95^{\circ} \mathrm{C}, 40\right.$ minutes) in the same buffer. The dilutions of primary antibodies were 1:1000
(KNY-379), 1:500 (anti-tubulin beta III and nestin), and 1:200 (anti-vimentin, GFAP, galactocerebroside, and NF). For controls, the primary antibodies were omitted or primary antibodies preadsorbed with excess homogenate or normal sera were used.

\section{Expression Cloning}

A cDNA library from whole fetal human brain (male/ female, 19-23 weeks, pooled) was purchased from Stratagene (La Jolla, California; catalog no. 937227). Using appropriately prepared host bacteria, XL1-Blue MRF strain, titering of lambda phages was performed according to the manufacturer's instructions. Tubes containing titered phages and host bacteria were incubated for 15 minutes at $37^{\circ} \mathrm{C}$ and $5 \mathrm{ml}$ of LB top agarose was added. The plating culture was poured onto LB agar plates, which were then inverted and incubated overnight at $42^{\circ} \mathrm{C}$. Isopropylthiogalactoside-saturated filters were placed on the surface of the agar in each plate and incubated at $37^{\circ} \mathrm{C}$ for 3 to 4 hours. The filters were removed, rinsed, and placed in block solution for 1 hour, then placed in KNY-379 1:1000 solution for 1 hour, rinsed, incubated with peroxidase-conjugated second antibody (anti-mouse Ig, Dako, Carpinteria, California) at a 1:1000 dilution for 1 hour, rinsed, and finally developed with 3,3'-diaminobenzidine. Positive plaques with KNY379 antibodies were picked and subcloned three times. The cDNA was amplified by PCR with T1 and T3 primers and subcloned into pT7BlueTM T vectors (Novagen, Madison, Wisconsin), transfected into Escherichia coli, and sequenced.

\section{Immunoprecipitation and Immunoblot Analysis}

Tissues stored in liquid nitrogen were pulverized, washed with PBS, homogenized with lysis buffer, and immunoprecipitated using a kit (Boehringer Mannheim, Mannheim, Germany) according to the manufacturer's instructions, using KNY-379. Both nonimmunoprecipitated and immunoprecipitated proteins were separated by electrophoresis on an SDSpolyacrylamide gel (5 20\%), transferred to a nitrocellulose membrane, and blotted with KNY-379. Immunopositive bands were detected with an immunoperoxidase Western blotting kit (Amersham). To determine whether there was cross-reactivity with vimentin or nestin, antibodies against vimentin or nestin were also applied to the immunoblots.

\section{Cell Culture from Human Fetal Brain Tissues}

Fetal brain tissue samples were mechanically dissected in DMEM/Ham's F-12 (1:1). After dissection, the tissue samples were enzymatically digested with 0.05\% trypsin/0.53 mм EDTA (Invitrogen, Carlsbad, California) for 20 minutes at $37^{\circ} \mathrm{C}$. The trypsin activity was then stopped by adding soybean trypsin inhibitor (2.8 mg/ml; Beringer). Cell suspensions were grown using the neurosphere method (Reynolds et al, 1992) in defined DMEM/F-12 (1:1)-based growth medium supplemented with human recombinant epidermal growth factor (20 ng/ml; Invitrogen), human recombi- 
nant fibroblast growth factor $2(20 \mathrm{ng} / \mathrm{ml}$; PeproTech Inc., Rocky Hill, New Jersey), human recombinant leukemia inhibitory factor (10 ng/ml; Chemicon), heparin (5 ng/ml; Sigma, St. Louis, Missouri), B27 supplement (Invitrogen), $15 \mathrm{~mm}$ HEPES, penicillin (100 U/ml), streptomycin $(100 \mathrm{ng} / \mathrm{ml})$, and amphotericin B (250 $\mathrm{ng} / \mathrm{ml})$. To induce differentiation, neurospheres were plated on polyornithine-coated glass coverslips and cultured in the same medium lacking the three growth factors and supplemented with $1 \%$ fetal bovine serum. The cells were cultured for 14 days before fixation for immunocytochemistry.

\section{Immunocytochemical Analysis}

Human neurospheres and coverslips with differentiated cells were fixed for 20 minutes at room temperature with $4 \%$ paraformaldehyde in PBS. After fixation, the neurospheres were dipped in 30\% sucrose/ PBS at room temperature for 30 minutes, embedded in OCT compound, sectioned on a cryotome at $12-\mu \mathrm{m}$ thickness, and mounted on coverslips. The sections of neurospheres were incubated with three primary antibodies: anti-human nestin (rabbit polyclonal,1:500); anti-Musashi1 (rat monoclonal, 14H1, 1:500) (Kaneko et al, 2000), which is an evolutionally conserved neural RNA-binding protein that is selectively expressed in neural stem cells and neuronal progenitors, astroglial progenitors, and mature astrocytes (Kaneko et al, 2000; Kanemura et al, 2001; Sakakibara and Okano, 1997; Sakakibara et al, 1996); and KNY-379 in PBS/ $0.1 \%$ Triton- $\mathrm{X} / 10 \%$ normal goat serum at $4^{\circ} \mathrm{C}$ overnight. The coverslips with differentiated cells were then incubated with another set of three primary antibodies: KNY-379 (1:1000), anti-PSA-NCAM (mouse IgM, 1:500; a kind gift from Dr. Seki, Department of Anatomy, Juntendo University School of Medicine) (Seki and Arai, 1993), and anti-GFAP (rabbit poly, 1:80; Sigma), under the same reaction conditions. After 3 washes, the neurosphere sections and coverslips with differentiated cells were incubated with the appropriate secondary antibodies (Alexa Fluor 488 goat anti-mouse IgG, Alexa Fluor 568 goat anti-rabbit IgG, Alexa Fluor 647 goat anti-rat IgG, and Alexa Fluor 647 goat anti-mouse IgM; Molecular Probes Inc., Eugene, Oregon) at room temperature for 1 hour. The sections were then examined using a laser scanning microscope (Carl Zeiss LSM510).

\section{Acknowledgement}

We thank the staff of the Department of Pathology, St. Mary's Hospital, for their assistance.

\section{References}

Akimoto J, Itoh H, Miwa T, and Ikeda K (1993). Immunohistochemical study of glutamine synthetase expression in early glial development. Brain Res Dev Brain Res 72:9-14.

Banerjee A, Roach MC, Wall KA, Lopata MA, Cleveland DW, and Luduena RF (1988). A monoclonal antibody against the type II isotype of $\beta$-tubulin: Preparation of isotypically altered tubulin. J Biol Chem 263:3029-3034.
Bentivoglio M and Mazzarello P (1999). The history of radial glia. Brain Res Bull 49:305-315.

Buc-Caron M-H (1995). Neuroepithelial progenitor cells explanted from human fetal brain proliferate and differentiate in vitro. Neurobiol Dis 2:37-47.

Canoll PD, Barnea G, Levy JB, Sap J, Ehrlich M, Silvennoinen O, Schlessinger J, and Musacchio JM (1993). The expression of a novel receptor-type tyrosine phosphatase suggests a role in morphogenesis and plasticity of the nervous system. Brain Res Dev Brain Res 75:293-298.

Cleveland DW (1987). The multitubulin hypothesis revisited: What have we learned? J Cell Biol 104:381-383.

Cleveland DW, Lopata MA, MacDonald RJ, Cowan NJ, Rutter WJ, and Kirschner MW (1980). Number and evolutionary conservation of alpha- and beta-tubulin and cytoplasmic beta- and gamma-actin genes using specific cloned cDNA probes. Cell 20:95-105.

Dahlstrand J, Zimmerman LB, McKay RD, and Lendahl U (1992). Characterization of the human nestin gene reveals a close evolutionary relationship to neurofilaments. J Cell Sci 103:589-597.

Declaration of Helsinki (Adopted in 1964 by the 18th World Medical Assembly in Helsinki, Finland, and revised by the 29th World Medical Assembly in Tokyo in 1975). In: Andrew C. Varga, editor. The main issue in bioethics, revised edition. New York: Paulist Press, 1984.

Edwards MA, Yamamoto M, and Caviness VS Jr (1990). Organization of radial glia and related cells in the developing murine CNS: An analysis based upon a new monoclonal antibody marker. Neuroscience 36:121-144.

Feng L and Heintz N (1995). Differentiating neurons activate transcription of the brain lipid-binding protein gene in radial glia through a novel regulatory element. Development 121: 1719-1730.

Fujita S (1963). The matrix cell and cytogenesis in the developing central nervous system. J Comp Neurol 120:3742.

Guide for the Care and Use of Laboratory Animals. NIH Publication No. 85-23 (revised 1985). Bethesda: National Institutes of Health.

Hartfuss E, Galli R, Heins N, and Gotz M (2001). Characterization of CNS precursor subtypes and radial glia. Dev Biol 229:15-30.

Heins N, Malatesta $P$, Cecconi F, Nakafuku M, Tucker KL, Hack MA, Chapouton P, Barde Y-A, and Gotz M (2002). Glial cells generate neurons: The role of the transcription factor Pax6. Nat Neurosci 5:308-315.

His W (1889). Die Neuroblasten und deren Entstehung im embryonalen Mark. Abh $\mathrm{Kgl}$ sachs Ges Wissensch math phys KI 15:311-372.

Hockfield S and McKay RD (1985). Identification of major cell classes in the developing mammalian nervous system. J Neurosci 5:3310-3328.

Hoffman PN and Cleveland DW (1988). Neurofilament and tubulin expression recapitulates the developmental program during axonal regeneration: Induction of a specific betatubulin isotype. Proc Natl Acad Sci USA 85:4530-4533.

Honig LS, Herrmann K, and Shatz CJ (1996). Developmental changes revealed by immunohistochemical markers in human cerebral cortex. Cereb Cortex 6:794-806. 
Jiang YQ and Oblinger MM (1992). Differential regulation of beta III and other tubulin genes during peripheral and central neuron development. J Cell Sci 103:643-651.

Kamei $\mathrm{Y}$, Inagaki N, Nishizawa M, Tsutsumi O, Taketani $\mathrm{Y}$, and Inagaki M (1998). Visualization of mitotic radial glial lineage cells in the developing rat brain by Cdc2 kinasephosphorylated vimentin. Glia 23:191-199.

Kaneko Y, Sakakibara S, Imai T, Suzuki A, Nakamura Y, Sawamoto K, Ogawa Y, Toyama Y, Miyata T, and Okano H (2000). Musashi1: An evolutionally conserved marker for CNS progenitor cells including neural stem cells. Dev Neurosci 22:139-153.

Kanemura Y, Mori K, Sakakibara S, Fujikawa $H$, Hayashi $H$, Nakano A, Matsumoto T, Imai I, Ohnishi T, Fushiki F, Nakamura Y, Yamasaki M, Okano H, and Arita N (2001). Musashi1, an evolutionarily conserved neural RNA-binding protein, is a versatile marker of human glioma cells in determining their cellular origin, malignancy, and proliferative activity. Differentiation 68:141-152.

Keyoung HM, Roy NS, Benraiss A, Louissaint A Jr, Suzuki A, Hashimoto K, Rashbaum WK, Okano H, and Goldman SA (2001). High-yield selection and extraction of two promoterdefined phenotypes of neural stem cells from the fetal human brain. Nature Biotech 19:843-850.

Kukekov VG, Laywell ED, Suslov O, Davies K, Scheffler B, Thomas LB, O'Brien TF, Kusakabe M, and Steindler DA (1999). Multipotent stem/progenitor cells with similar properties arise from two neurogenic regions of adult human brain. Exp Neurol 156:333-344.

Lee MK, Tuttle JB, Rebhun LI, Cleveland DW, and Frankfurter A (1990). The expression and posttranslational modification of a neuron-specific beta-tubulin isotype during chick embryogenesis. Cell Motil Cytoskel 17:118-132.

Lendahl U, Zimmerman LB, and McKay RDG (1990). CNS stem cells express a new class of intermediate filament protein. Cell 60:585-595.

Levitt P, Cooper ML, and Rakic P (1981). Coexistence of neuronal and glial precursor cells in the cerebral ventricular zone of the fetal monkey: An ultrastructural immunoperoxidase analysis. J Neurosci 1:27-39.

Lewis SA, Lee MG, and Cowan NJ (1985). Five mouse tubulin isotypes and their regulated expression during development. J Cell Biol 101:852-861.

Lopata MA and Cleveland DW (1987). In vivo microtubules are copolymers of available beta-tubulin isotypes: Localization of each of six vertebrate beta-tubulin isotypes using polyclonal antibodies elicited by synthetic peptide antigens. J Cell Biol 105:11707-11720.

Malatesta P, Hartfuss E, and Gotz M (2000). Isolation of radial glial cells by fluorescent-activated cell sorting reveals a neuronal lineage. Development 127:5253-5263.

McKay R (1997). Stem cells in the central nervous system. Science 276:66-71.

Misson J-P, Edwards MA, Yamamoto M, and Caviness VS Jr (1988). Identification of radial glial cells within the developing murine central nervous system: Studies based upon a new immunohistochemical marker. Brain Res Dev Brain Res 44: 95-108.

Miyata T, Kawaguchi A, Okano H, and Ogawa M (2001). Asymmetric inheritance of radial glial fibers by cortical neurons. Neuron 31:727-741.
Moody SA, Miller V, Spanos A, and Frankfurter A (1996). Development expression of a neuron-specific $\beta$-tubulin in frog (Xenopus laevis): A marker for growing axons during the embryonic period. J Comp Neurol 364:219-230.

Nakamura Y, Yamamoto M, and Kumamaru E (1998). A variant very low density lipoprotein receptor lacking 84 base pairs of O-linked sugar domain in the human brain myelin. Brain Res 793:47-53.

Nakanishi K, Maruyama M, Shibata T, and Morishima N (2001). Identification of a caspase- 9 substrate and detection of its cleavage in programmed cell death during mouse development. J Biol Chem 276:41237-41244.

Noctor SC, Flint AC, Weissman TA, Dammerman RS, and Kriegstein AR (2001). Neurons derived from radial glial cells establish radial units in neocortex. Nature 409:714-720.

Nothias F, Fischer I, Murray M, Mirman S, and Vincent JD (1996). Expression of a phosphorylated isoform of MAP1B is maintained in adult central nervous system areas that retain capacity for structural plasticity. J Comp Neurol 368:317334.

Ohyu J, Yamanouchi H, and Takashima S (1997). Immunohistochemical study of microtubule-associated protein 5 (MAP5) expression in the developing human brain. Brain Dev 19:541-546.

Orlik O and Altaner C (1988). Modifications of hybridoma technology which improve the yield of monoclonal antibody producing cells. J Immunol Methods 115:55-59.

Paden CM, Zhou X, Watt JA, Burton R, Pickett J, and Oblinger MM (1995). Distribution of growth-associated class I alpha-tubulin and class II beta-tubulin mRNAs in adult rat brain. J Comp Neurol 362:368-384.

Parnavelas JG and Nadarajah B (2001). Radial glial cells: Are they really glia? Neuron 31:881-884.

Pincus DW, Keyoung HM, Harrison-Restelli C, Goodman RR, Fraser RAR, Edgar M, Sakakibara S, Okano H, Nedergaard M, and Goldman SA (1997). Fibroblast growth factor-2/brainderived neurotrophic factor-associated maturation of new neurons generated from adult human subependymal cells. Ann Neurol 43:576-585.

Prada FA, Dorado ME, Quesada A, Prada C, Schwarz U, and de la Rosa EJ (1995). Early expression of a novel radial glia antigen in the chick embryo. Glia 15:389-400.

Rakic $P$ (1972). Mode of cell migration to the superficial layers of fetal monkey neocortex. J Comp Neurol 145:61-83.

Rakic P (1995). Radial glial cells: Scaffolding for brain construction. In: Kettenmann $\mathrm{H}$ and Ronsom BR, editors. Neuroglia. New York: Oxford University Press, 746-762.

Ramon Y and Cajal S (1911). In: Histologie du systeme nerveux de l'hommes et des vertebres. Paris: Maloine.

Reynolds BA, Tetzlaff W, and Weiss SA (1992). Multipotent EGF-responsive striatal embryonic progenitor cell produces neurons and astrocytes. J Neurosci 12:4565-4574.

Robertson MD, Toews AD, Goodrum JF, and Morell P (1992). Neurofilament and tubulin mRNA expression in Schwann cells. J Neurosci Res 33:156-162.

Roy NS, Wang S, Jiang L, Kang J, Benraiss A, HarrisonRestelli C, Fraser RAR, Couldwell WT, Kawaguchi A, Okano $\mathrm{H}$, Nedergaard M, and Goldman SA (2000). In vitro neurogenesis by progenitor cells isolated from the adult human hippocampus. Nat Med 6:271-277. 
Sakakibara S, Imai T, Aruga J, Nakajima K, Yasutomi D, Nagata T, Kurihara Y, Uesugi S, Miyata T, Ogawa M, Mikoshiba K, and Okano H (1996). Mouse-Musashi-1, a neural RNA-binding protein highly enriched in the mammalian CNS stem cell. Dev Biol 176:230-242.

Sakakibara S and Okano H (1997). Expression of neural RNA-binding proteins in the post-natal CNS: Implication of their roles in neural and glial cell development. J Neurosci 17:8300-8312.

Sarnet HB (1998). Vimentin immunohistochemistry in human fetal brain: Methods of standard incubation versus thermal intensification achieve different objectives. Pediatr Dev Pathol 1:222-229.

Schluesenser HJ and Meyermann R (1994). Expression of BMP-6, a TGF-beta related morphogenic cytokine, in rat radial glial cells. Glia 12:161-164

Seki T and Arai Y (1993). Distribution and possible roles of a highly polysialylated neural cell adhesion molecule (NCAM-H) in the developing and adult central nervous system. Neurosci Res 17:265-290.
Sullivan KF (1988). Structure and utilization of tubulin isotypes. Annu Rev Cell Biol 4:687-716.

Svendsen CN, Bhattacharyya A, and Tai YT (2001). Neurons from stem cells: Preventing an identity crisis. Nat Rev Neurosci 2:831-834.

Walsh C and Cepko CL (1992). Widespread dispersion of neuronal clones across functional regions of the cerebral cortex. Science 255:434-440.

Yachnis AT, Rorke LB, Lee VM-Y, and Trojanowski JQ (1993). Expression of neuronal and glial polypeptides during histogenesis of the human cerebellar cortex including observations on the dentate nucleus. J Comp Neurol 334:356-369. 